\title{
STATUS REPORT ON SAMPLE PREPARATION PROTOCOLS DEVELOPED AT THE LMC14 LABORATORY, SACLAY, FRANCE: FROM SAMPLE COLLECTION TO ${ }^{14} \mathrm{C}$ AMS MEASUREMENT
}

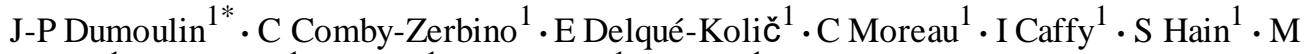 \\ Perron $^{1} \cdot$ B Thellier $^{1} \cdot$ V Setti $^{1} \cdot$ B Berthier $^{1} \cdot$ L Beck $^{1}$ \\ Laboratoire de Mesure du Carbone 14 (LMC14), LSCE/IPSL, CEA-CNRS-UVSQ, Université Paris-Saclay, F-91191 Gif- \\ sur-Yvette, France.
}

\begin{abstract}
The main objective of this report is to present the dating process routinely applied to different types of samples at the Laboratoire de Mesure du Carbone 14 (LMC14). All the results and protocols refer to our procedures over the last 5 years. A description of the sorting and chemical pretreatments of the samples as well as the extraction and graphitization of $\mathrm{CO}_{2}$ are reported. Our last study concerning the degradation of the blank level according to the storage time of the targets between graphitization and accelerator mass spectrometry (AMS) measurement is also presented. This article also provides information on how to submit a valid laboratory sample. We give details relating to sampling procedures on site as well as contamination is sues relative to the ${ }^{14} \mathrm{C}$ dating methodology.
\end{abstract}

KEYWORDS: pretreatment, radiocarbon AMS dating, status report, contamination.

\section{INTRODUCTION}

The Laboratoire de Mesure du Carbone 14 (LMC14) was established in 2003 in France. The facility is dedicated to high-precision radiocarbon measurement for the following research institutions: the Commissariat à l'Energie Atomique et aux Energies Alternatives (CEA), the Centre National de la Recherche Scientifique (CNRS), the Institut de Recherche pour le Développement (IRD), the Institut de Radioprotection et de Sureté Nucléaire (IRSN), and the Ministère de la Culture et de la Communication (MCC). The accelerator mass spectrometer (AMS), called ARTEMIS, is based at the CEA center in Saclay. Graphite sample preparation is adjacent to the spectrometer area, whereas the $\mathrm{CO}_{2}$ samples are produced at the CNRS campus in Gif-sur-Yvette.

Over many years, we have improved our protocols in order to extend the range of datable samples. About 4500 samples, corresponding to unknown samples, standards, and blanks, are measured every year including more than 200 samples dedicated to specific LMC14 research programs (Quiles et al. 2013; Leroy et al. 2015). Various types of raw samples are prepared and measured such as organic matter, carbonate, and, more recently, dissolved inorganic carbon (DIC) in water (Dumoulin et al. 2013) and archaeological iron alloys (Leroy et al. 2015). The ${ }^{14} \mathrm{C}$ analysis of very small samples (below $0.5 \mathrm{mg}$ of carbon down to $10 \mu \mathrm{g}$ of carbon) has also been explored (Delqué-Količ et al. 2013a, 2013b). Different fields of research related to our institutions are covered, including archaeology (Genty et al. 2011; Fontugne 2013; Fontugne et al. 2013; Valladas et al. 2013), museum applications (Richardin et al. 2013), studies on the carbon cycle in rivers (Coularis et al. 2016) and in oceans (Tisnérat-Laborde et al. 2013), and paleocontinental research (Hatté et al. 2013). Depending on the institution, the LMC14 operates either the full preparation of the samples or only the graphitization of the samples received in $\mathrm{CO}_{2}$ form. Archaeological samples and particularly bone samples are prepared in other laboratories (CDRC in Lyon, MNHN and C2RMF in Paris) and sent stored in sealed tubes.

The carbon isotopes are measured with the Artemis AMS facility of the LMC14. This facility is based on a 9SDH-2 Pelletron tandem from National Electrostatic Corporation (NEC). The spectrometer has been fully devoted to ${ }^{14} \mathrm{C}$ measurements since 2003 (Cottereau et al. 2007; Moreau et al. 2013).

\footnotetext{
*Corresponding author. Email: dumoulin@lsce.ipsl.fr.
} 
This status report provides crucial information about sample collection and contamination problems. It also explains how best to submit samples to dating laboratories. The report then focuses on the sample preparation techniques used at the LMC14. The preparation lines and the specific protocols applied routinely or developed during the last 5 years are described. Finally, our latest studies on graphitization procedures and on the storage duration of $\mathrm{CO}_{2}$ tubes and targets are presented.

\section{SAMPLE COLLECTION AND SUBMISSION}

As a standard procedure at our facility, we recommend users to contact the laboratory to present their projects. We explain to them the appropriate sampling strategies as well as the proper sample storage for the material selected for a ${ }^{14} \mathrm{C}$ dating.

During sample collection, it is recommended to use very clean tools and receptacles. The site has to be completely cleared of cigarette ash, clothing fibers, hairs, or food crumbs to avoid adding exogenous carbon to the sample. Charcoal, wood, plant remains, or peat are preferred to bulk soil or sediment which can contain different sources of carbon. For shells or for-aminifera, it is recommended to choose the same species that live nearby in the water column. Species from the surface such as planktonic foraminifera will not have the same reservoir age as species living in the bottom as benthic foraminifera.

The best containers are aluminum foil, glass bottles, or plastic bags but not of all types. Indeed, it is advised to choose polyethylene containers and not other plastics, which can exchange carbon with the sample (Gillespie 1984). It is important not to use paper, envelopes, cardboard, or tissues as a container and to not label the sample name directly on the collected material. It is better to send dry samples. If that is not possible and the samples are wet, directions should be given to store them in a fridge at $4^{\circ} \mathrm{C}$ to avoid any contamination with mold growth or bacteria.

Table 1 shows the approximate amount of raw material to be shipped to the laboratory before chemical pretreatment and also the amount of clean material needed for $\mathrm{CO}_{2}$ production

Table 1 Amount of raw material to be shipped to the laboratory before chemical pretreatment and amount of clean material to produce a 1-mg carbon graphite target. The indicated mass is for dry material.

\begin{tabular}{lll}
\hline & \multicolumn{2}{c}{ Mass (mg) } \\
\cline { 2 - 3 } Nature & Raw material & Cleaned material \\
\hline Shell & $50-200$ & 10 \\
Coral & $50-200$ & 10 \\
Foraminifera & 10 & 10 \\
Calcite powder & $10-20$ & 10 \\
Wood & $50-100$ & 3 \\
Plant & $50-100$ & 3 \\
Charcoal & $10-50$ & 2.5 \\
Peat & $50-100$ & $3-5$ \\
Sediments/soils & $1000-5000$ & According to the \% TOC \\
Iron & According to the \%TOC & \\
Water (for DIC) & According to the TIC of the water \\
\hline
\end{tabular}

Note: TOC $=$ total organic carbon; TIC $=$ total inorganic carbon; DIC: dis solved inorganic carbon. 
equivalent to a 1-mg carbon graphite. It is always advisable to provide more sample material than the minimum requested. In this case, the laboratory can return the unused sample.

It is very important to provide as much information as possible about the samples to the laboratory: the aim of the study, the sample reference, the location and site description, the potential environmental contaminations, the sample nature, and the possible treatments already done before the submission. All these details about the samples are registered in our database and a unique laboratory code number is given to each sample. This number will identify the sample during the entire dating process and will be given with the results to be used in every communication and publication.

\section{SAMPLE PREPARATION}

\section{General Considerations}

Different types of samples such as organic matter, carbonates, DIC from water, and iron alloys are analyzed at the LMC14. Examination and pretreatment are needed to remove carbon of external origin, which can alter the real age of the sample. The main issue is to date only the material related to the event studied and it is also important to point out that there is no chemical pretreatment, which can guarantee a total removal of the contaminants. Further, the efficiency of the chemical treatment is often connected to the size (pollen, microcharcoals) or the brittleness (leather, skin) of the sample. Sometimes, it is preferable to stop or to apply a softer chemical treatment rather than to lose the entire sample.

For macrocontaminants, an inspection with a microscope is enough to remove rootlets, hair, or fibers. Note that rootlets or hair bring modern carbon to the sample (close to actual ${ }^{14} \mathrm{C}$ atmospheric contents), whereas synthetic fibers made with petroleum products bring old dead carbon (carbon free of ${ }^{14} \mathrm{C}$ ).

For the removal of molecular contaminants such as carbonates or humic acids, a chemical pretreatment is required. Carbonates are present in almost all soil types and can be dissolved in the water so they can be present in almost every material. Most geological carbonates are very old and can bring a lot of dead carbon to the sample, so all organic matters are carefully decarbonated with acid. We can also find young or old carbonate contaminations with shells or corals due to the recrystallization of the original aragonite of the sample into calcite. This recrystallization occurs often at the surface of the sample and can be removed by sand blasting or acid cleaning. The recrystallization of aragonite to calcite results from an exchange of carbon with a different isotopic composition, so this is detectable with X-ray diffraction or infrared spectroscopy. Humic and fulvic acid are the main components of humic substances, the major organic constituents of soil (humus). Fulvic acids are humic acids of lower molecular weight and higher oxygen content. Both humic and fulvic acids are mobile in soils and can form complexes with ions found in the environment. They can also be clustered in the porous structures of wood, charcoals, or bones and have to be removed from the original material. Humic acids are soluble in an alkaline solution and precipitate in acid. Fulvic acids are soluble both in acid and alkali. The residue after these two chemical steps is called humin and is the most useful part for ${ }^{14} \mathrm{C}$ dating (Brock et al. 2010) because it is very close to the original carbon material deposited at the time of the studied event. The chemical pretreatments according to the sample nature are detailed in the next section.

To avoid any contaminations by external carbon during the sample preparation process, a special procedure is applied to clean any glassware and tools susceptible to be in contact with 
the sample. First, the glassware is boiled at $100^{\circ} \mathrm{C}$ in presence of a lab detergent and then washed with normal water. Then, the glassware is placed overnight in a $10 \% \mathrm{HCl}$ bath to remove eventual carbonates and washed the day after with deionized water. Each piece of glassware is covered with an aluminum foil and baked at $450^{\circ} \mathrm{C}$ during $5 \mathrm{hr}$ to remove remaining organic contaminants. Stainless steel tools which cannot be baked are hand-washed with TFD4, rinsed with deionized water, cleaned again in alcohol in an ultrasonic bath, and finally dried in a $60^{\circ} \mathrm{C}$ oven.

To control the chemical pretreatment step, standards and blanks are treated in the same way and at the same time as the samples. A blank is a ${ }^{14} \mathrm{C}$-free sample, which is measured to know if we brought contaminations during the dating process. For standards, we use different types of FIRI samples (Fourth International Radiocarbon Intercomparison, Scott 2003). Table 2 shows which standards and blanks are used according to the type of samples. The ${ }^{14} \mathrm{C}$ results we obtain for the international standards compared to the consensus values are also indicated in this table.

\section{Microscopic Examination}

An examination of the samples is carried out under a microscope to check their nature and to verify if the treatment method suggested after reading the proposal is applicable. For example, a sample indicated as a charcoal may exhibit no wood structure under the microscope and consequently is reidentified as manganese oxide. Also, a sample given as wood can be totally petrified and free of carbon because all of the organic materials have been replaced with minerals, often mostly silicates, while retaining the original structure of the stem tissue.

During sample examination under the microscope, fibers, rootlets, and mineral grains are carefully removed. When the targeted material has not been separated by the submitter, it is the moment to pick up microcharcoals or plant remains from bulk soil.

\section{Chemical Pretreatment}

The chemical pretreatment for removing molecular contaminants is described according to the nature of the sample.

\section{Organic Samples}

Our methodology can be applied to wood, charcoal, plant, seed, peat, sediment, textile, leather, and tissue samples. Most of the samples are pretreated using the classical acid $(\mathrm{HCl})$-alkali $(\mathrm{NaOH})$-acid $(\mathrm{HCl})$ method adapted according to the fragility and the available amount of the sample. Between each step of acid or alkali the samples are washed with deionized water (Millipore $\left.^{(}\right)$reverse osmosis water, $\mathrm{COT}<5 \mathrm{ppb}$ ) until a neutral $\mathrm{pH}$ is reached.

The first acid wash $\left(0.5 \mathrm{M} \mathrm{HCl}\right.$ at $80^{\circ} \mathrm{C}$ for $\left.1 \mathrm{hr}\right)$ is used to remove carbonates from the samples. Then, the sample undergoes an alkali wash $\left(0.1 \mathrm{M} \mathrm{NaOH}\right.$ at $80^{\circ} \mathrm{C}$ for $\left.1 \mathrm{hr}\right)$ in order to remove organic contaminants like humic and fulvic acid. This step is the most critical for the sample and must be adapted to avoid the total dissolution of the sample. For fragile samples, heating is often avoided, and if the solution immediately becomes totally black, some deionized water must be quickly added to stop the reaction. If the sample amount is sufficient, several $\mathrm{NaOH}$ washings can be applied until no coloration (due to the dissolution of the humic fraction) occurs. Finally, a second acid washing $\left(0.5 \mathrm{M} \mathrm{HCl}\right.$ at $80^{\circ} \mathrm{C}$ for $\left.1 \mathrm{hr}\right)$ is applied to the sample to dissolve modern atmospheric carbon dioxide possibly adsorbed during the alkali step (Goh and Molloy 1972; Hatté et al. 2001). 
Table 2 Standards and blanks used according to the type of samples. LMC14 data have been obtained between 2010 and 2015 and s amples have been measured less than 30 days after the graphitization step. LMC14 ${ }^{14} \mathrm{C}$ mean values are compared to consensus values.

\begin{tabular}{|c|c|c|c|c|c|c|c|c|c|c|c|}
\hline \multirow[b]{3}{*}{$\begin{array}{l}\text { Name } \\
\text { Blank }\end{array}$} & \multirow{3}{*}{$\begin{array}{l}\# \\
\text { Targets } \\
\text { measured }\end{array}$} & \multirow[b]{3}{*}{$\begin{array}{l}\text { Nature of the } \\
\text { sample associated }\end{array}$} & \multirow[b]{3}{*}{ Treatment } & \multicolumn{4}{|c|}{ Consensus value } & \multicolumn{4}{|c|}{ LMC14 mean value } \\
\hline & & & & \multicolumn{2}{|c|}{$\mathrm{pMC}$} & \multicolumn{2}{|l|}{$\mathrm{BP}$} & \multicolumn{2}{|c|}{$\mathrm{pMC}$} & \multicolumn{2}{|c|}{${ }^{14} \mathrm{C}$ age $\mathrm{BP}$} \\
\hline & & & & Average & $\sigma$ & Average & $\sigma$ & Average & $\sigma$ & Average & $\sigma$ \\
\hline $\begin{array}{l}\text { Border cave (wood } \\
\text { charcoal) }\end{array}$ & 115 & Organic matter & $\begin{array}{l}\text { AAA } \\
\text { acid-alkali-acid }\end{array}$ & & & & & 0.326 & 0.115 & 46,465 & 2760 \\
\hline IAEA C1 marble & 93 & $\begin{array}{l}\text { Calcite } \\
\text { Corals* } \\
\text { Foraminifera* }\end{array}$ & $\begin{array}{l}\text { NHNO3 } 10^{-2} \mathrm{M} \\
15 \mathrm{mn}\end{array}$ & 0 & 0.02 & & & 0.154 & 0.072 & 52,841 & 3600 \\
\hline $\begin{array}{l}\text { Tridacna (giant clam } \\
\text { shell) } \\
\text { Standards }\end{array}$ & 21 & Shell & $\begin{array}{l}\mathrm{NHNO}_{3} 10^{-2} \mathrm{M} \\
15 \mathrm{mn}\end{array}$ & & & & & 0.138 & 0.047 & 53,409 & 3044 \\
\hline FIRI G (barley mash) & 34 & Modern samples & No & 110.70 & 0.04 & & & 110.66 & 0.42 & & \\
\hline $\begin{array}{l}\text { FIRI C (turbidite } \\
\text { carbonate) }\end{array}$ & 57 & $\begin{array}{l}\text { Carbonates } \\
\text { samples }\end{array}$ & $\begin{array}{l}\text { Deionized water } \\
\text { wash }\end{array}$ & & & 18,176 & 11 & 10.337 & 0.165 & 18,232 & 128 \\
\hline IAEA C2 (travertine) & 64 & $\begin{array}{l}\text { Carbonates } \\
\text { samples }\end{array}$ & $\begin{array}{l}\mathrm{NHNO}_{3} 10^{-2} \mathrm{M} \\
15 \mathrm{mn}\end{array}$ & 41.14 & 0.03 & & & 41.05 & 0.34 & 7153 & 66 \\
\hline FIRI H (wood) & 172 & Organic matter & $\begin{array}{l}\text { AAA } \\
\text { acid-alkali-acid }\end{array}$ & & & 2232 & 5 & 75.66 & 0.31 & 2241 & 32 \\
\hline FIRI I (cellulose) & 171 & Organic matter & No & & & 4485 & 5 & 51.162 & 0.221 & 4493 & 31 \\
\hline FIRI E (humic acid) & 62 & Organic matter & No & & & 11,780 & 7 & 23.005 & 0.178 & 11,805 & 62 \\
\hline
\end{tabular}

*For corals and foraminifera we use very old samples from the bottom of the core as blanks if they are available. If not, $\mathrm{C} 1$ is used. 
In case of very small and/or fragile samples, a simple acid wash $(0.5 \mathrm{M} \mathrm{HCl}$ at room tempera-ture $)$ can be applied to preserve the sample. It should be noted that if the cleaning step is shortened to preserve the sample, there is no way to guarantee that all contaminants were removed and that the final age may be not affected by the residues of labile carbon.

Sediments undergo the first $0.5 \mathrm{~N} \mathrm{HCl}$ acid wash over $24 \mathrm{hr}$. If a strong bubbling occurs during the first treatment, the acid solution has to be changed several times. When the $\mathrm{pH}$ stays acid and becomes no longer neutral, the sediments are covered with an aluminum foil and stay in acid overnight. The following day, the bulk is rinsed with deionized water up to a neutral $\mathrm{pH}$ and then dried in the oven at $60^{\circ} \mathrm{C}$. At this stage, we carry out our own $\%$ TOC (total organic carbon) analysis using an elementary analyzer to determine the content of organic carbon in the sample. If the \% TOC is very low (less than 1 or $2 \%$ ) the chemistry is stopped to preserve the small amount of carbon. If the \% TOC is higher, the two other alkaline and acid washing steps are applied.

\section{Carbonates}

Dated samples include calcite, speleothems, corals, shells, or foraminifera. After removing any surface contamination by sand blasting the outer surface of shells and corals, the samples are cleaned with distilled water in an ultrasonic bath for $5 \mathrm{~s}$, and then washed by a gentle $\mathrm{HNO}_{3}$ acid solution $\left(10^{-2} \mathrm{M}\right)$ to remove organic contaminants. When the sample is large enough, the outer carbonate layer, which may have recrystallized, is removed in a $0.3 \mathrm{M} \mathrm{HCl}$ solution for $10-15 \mathrm{~min}$ until that a loss of weight of $40 \%$ is achieved. For calcite powder taken directly in the middle of the speleothem (by cutting and drilling), no chemical pretreatment is applied.

\section{Iron Samples}

A specific methodology has been developed in collaboration with the Laboratoire Archéomatériaux et Prévision de l'Altération (CEA-CNRS, Saclay, France) to prepare iron samples for

${ }^{14} \mathrm{C}$ dating. Thanks to this protocol, described by Leroy et al. (2015), potential con-taminations due to recycling of iron, cementing process, and postdepositional corrosion are avoided. The sample is cross-sectioned and polished to exclude corrosion layers and to analyze the slag inclusions entrapped in the metal. This last step is necessary to identify if different pieces of metal have been used to manufacture the object to be dated. After different cleaning $\left(4 \% \mathrm{HNO}_{3}\right.$, deionized water, ethanol), the most carburized zones with the higher carbon content are selected by a metallographic observation and collected with a TiN or CoB coated drill. A sufficient quantity of the sample according to the \% TOC of the sampled zones is sealed with an excess of $\mathrm{CuO}$ and a $1-\mathrm{cm}$ pure $\mathrm{Ag}$ wire. As recommended by Hüls et al. (2004), combustion with a $\mathrm{CuO} /$ sample ratio of 5 provides a sufficient excess of oxygen and ensures an optimal extraction ratio. For example, if the \% TOC of the iron sample is $0.5 \%, 200 \mathrm{mg}$ of iron is introduced in quartz sealed tube with $1 \mathrm{~g}$ of $\mathrm{CuO}$. The tubes are then heated at $850^{\circ} \mathrm{C}$ for $5 \mathrm{hr}$ to combust the sample and cooled slowly overnight as for the other organic matter samples.

\section{Water Samples}

For water samples, we only proceed to the extraction and the ${ }^{14} \mathrm{C}$ measurement of the DIC fraction of the water and not the DOC fraction (Dumoulin et al. 2013). Water samples do not need any pretreatment, but might be poisoned with $2 \mathrm{~mL}$ of $\mathrm{HgCl}_{2}$ in order to preserve the original amount of DIC by avoiding the mineralization of the DOC in DIC by the micro-organisms. With water containing little organic compounds such as natural groundwaters, this step is not necessary. In those cases, the bottles can be stored directly at $4{ }^{\circ} \mathrm{C}$ in the fridge and 
have to be measured as soon as possible. Containers such as glass bottles closed with free carbon grease $\left(\right.$ Apiezon $\left.^{(}\right)$) are preferred instead of plastic bottles, which can be more gas permeable or leak from their caps. In this case, the water runs the risk of equilibrating with the modern $\mathrm{CO}_{2}$ of the atmosphere. Water samples can be frozen, but only when we are sure that the container is perfectly closed so that the water will not exchange with the atmosphere during defrosting.

\section{Microsamples}

Microsamples (under $0.2 \mathrm{mg}$ ) contain a sufficient amount of carbon but have a very small size, such as microcharcoals, pollen grains, small amounts of foraminifera, etc. In these cases, the chemistry is very critical and has often to be modified to preserve the sample. Sometimes, a direct combustion is recommended after a discussion with the submitter about the risk of trying to apply a chemistry. Standards and blanks with the same range of mass are produced at the same time as the sample to quantify the modern carbon contamination introduced during all the preparation process. The measured ${ }^{14} \mathrm{C}$ activities of the ${ }^{14} \mathrm{C}$-free blank are used to correct the small samples ${ }^{14} \mathrm{C}$ activity according to their masses (Delqué-Količ et al. 2013a, 2013b).

\section{CO2 EXTRACTION AND GRAPHITIZATION}

\section{Laboratory Setup}

For our routine sample production, different vacuum lines are available in order to produce approximately 24 graphite targets every day. Twelve $\mathrm{CO}_{2}$ samples are produced from raw material by our laboratory and the rest is composed of $\mathrm{CO}_{2}$ samples in Pyrex sealed tubes coming from other laboratories.

A semi-automated rig is dedicated to the $\mathrm{CO}_{2}$ collection of the organic matters. It was designed from the LSCE semi-automated prototype (Hatté et al. 2003). During the past years, this line has been further developed to allow offline combustion of the sample with sealed tubes instead of an online automated combustion. Technical ways to install sealed tubes on our semi-automated rig have been investigated and a special inlet glass system has been developed. An offline combustion in sealed tube $\left(5 \mathrm{hr}, 850^{\circ} \mathrm{C}\right)$ allows sample production every day instead of every 2 days and a better purification of the $\mathrm{CO}_{2}$ is provided. Indeed, online combustion induces a temperature gradient between the bottom of the tube, which is very hot, and the upper part of the tube, which stays cold. The gas that stays in the colder part of the tube cannot be in contact with the Ag wire and is not well purified. Combustion with sealed tubes allows an efficient gas cleaning thanks to a direct contact of the gas with the $\mathrm{Ag}$ wire as well as the $\mathrm{Cu}$ coming from the $\mathrm{CuO}$. This continuous contact and the homogeneity of the temperature during the cooling help to reduce the problems which could occur during the graphitization step.

A second semi-automated rig is dedicated to the acid hydrolysis and the $\mathrm{CO}_{2}$ collection of the carbonates (Tisnérat-Laborde et al. 2001). Five carbonate samples can be produced in this way every day. A manual glass vacuum system is also available and can be used for the extraction of carbonates and organic matters. The vacuum $\left(5 \times 10^{-6} \mathrm{mbar}\right)$ is provided thanks to the combination of a primary dry pump and a secondary turbopump. The choice to work with such a low vacuum is explained not only by the need to work without any atmospheric $\mathrm{CO}_{2}$ but also because it is easier to detect possible microleaks. This line is also very useful when a lot of quartz tubes have to be sealed at the same time.

A small sealing line dedicated to seal five quartz tubes a day is also used. The geometry is quite compact with large glass tubes for a good pumping efficiency. The pumping group is composed 
of a primary pump and a turbopump to work at low vacuum $\left(5 \times 10^{-6} \mathrm{mbar}\right)$. The tubes are sealed individually with a butane/oxygen torch after the samples have been dried in a small portable oven. Each sample is heated up to $100^{\circ} \mathrm{C}$ to remove residual water. The evaporation is monitored with the pressure gauge (Pirani). This step is essential to remove all the water from the sample and avoid tubes exploding during the combustion at $850^{\circ} \mathrm{C}$. An explosion is unlikely with charcoals or wood, but can happen with soils and sediments. For example, clay with its layered structure can trap a large amount of water. Furthermore, sediments have a high surface area and, once dried, they tend to trap $\mathrm{CO}_{2}$ or volatile organic compounds (VOCs). In this case, a $100^{\circ} \mathrm{C}$ heating is required to remove all the water before the sealing.

A manual system to extract DIC from water samples was also built in 2013. This equipment is able to handle both seawater and freshwater. For the DIC extraction, we chose to work in a dynamic system with a He flux (Bard et al. 1989; Leboucher et al. 2004). The $\mathrm{CO}_{2}$ is produced with the introduction of $2 \mathrm{~mL}$ of phosphoric acid in the water sample. Then, the gas passes through two water traps at $-78^{\circ} \mathrm{C}$. Two aliquots are collected in liquid nitrogen: one for AMS and the other for $\delta^{13} \mathrm{C}$ measurement with a conventional mass spectrometer (Dumoulin et al. 2013).

The graphitization facility previously described by Cottereau et al. (2007) was improved and 24 $\mathrm{CO}_{2}$ samples are now reduced every day due to the two custom-made automatic benches. Both systems contain 12 reactors of 18 and $12 \mathrm{~mL}$, respectively. The lines are made of electropolished stainless steel and evacuated under $10^{-5}$ mbar with turbomolecular pumps backed by dry pumps. A multitemperature device, equipped with a heating resistance and plunged in liquid nitrogen, is used for trapping $\mathrm{CO}_{2}$ or water during the reaction.

A third bench was built for samples with carbon mass between 10 and $150 \mu \mathrm{g}$. It is composed of three reduction lines with smaller inner volume $(6 \mathrm{~mL})$ where chemical water traps $\left[\mathrm{Mg}\left(\mathrm{ClO}_{4}\right)_{2}\right]$ replace the usual multitemperature devices (Delqué-Količ et al. 2013a, 2013b).

\section{METHODS}

After the chemical pretreatment of organics, samples are dried under vacuum overnight $\left(60^{\circ} \mathrm{C}\right.$ under 0.1 mbar). Argon gas is used to break the vacuum in order to avoid modern $\mathrm{CO}_{2}$ to be sucked in the porosity of the sample. The appropriate amount of material (Table 1) is placed in a quartz tube with an excess of $\mathrm{CuO}(400-500 \mathrm{mg}$ ) and 1-cm Ag wire. The quartz tube is then sealed under vacuum $\left(5 \times 10^{-6}\right.$ mbar $)$. Seven organic sample tubes can be heated together $\left(850^{\circ} \mathrm{C}\right.$, $5 \mathrm{hr}$ ) in an external oven during the night.

$\mathrm{CO}_{2}$ gas is separated from $\mathrm{H}_{2} \mathrm{O}$ using a dry-ice/alcohol trap $\left(-78^{\circ} \mathrm{C}\right)$ and the pressure of each sample is measured to know the exact carbon content. In this way, $12 \mathrm{CO}_{2}$ samples can be processed every day (five carbonate samples and seven organic samples). The samples are cryogenically collected into vials to be transferred to the two graphitization lines.

After the chemical pretreatment of carbonates, five clean carbonate samples can be placed together on our semiautomatic system under vacuum overnight to be dried. Once the vacuum is under $10^{-5}$ mbar, $\mathrm{CO}_{2}$ can be produced by pure acid $\left(\mathrm{H}_{3} \mathrm{PO}_{4}\right)$ hydrolysis of carbonates. It is very important to wait for the complete acid reaction of the samples to avoid any sample fractionation.

Graphite targets are produced by reduction of the $\mathrm{CO}_{2}$ samples by hydrogen over iron catalyst following the reaction described by Vogel et al. (1984). On each bench, two reactors are 
dedicated to the graphitization of the oxalic acid II (Ox-II) normalizing standard, while the other 10 produce the unknown, the reference, and the blank samples. The ampoules or the sealed glass tubes containing the $\mathrm{CO}_{2}$ samples are hooked to the benches and the lines are evacuated under $10^{-}$ 5 mbar. The iron powder (Merck, particle size $10 \mu \mathrm{m}$ ) is degassed for $1 \mathrm{hr}$ at $600^{\circ} \mathrm{C}$ under vacuum before the reaction. Hydrogen is introduced in the reduction line with a $\mathrm{H}_{2} / \mathrm{CO}_{2}$ ratio of 2.5 approximately. The iron is heated at $600^{\circ} \mathrm{C}$ while the water is trapped at

$-78^{\circ} \mathrm{C}$. The pressure in the reaction lines is monitored and the reduction ends when the slope of the pressure becomes smaller than $0.3 \%$. Samples of $1 \mathrm{mg} \mathrm{C}$ are reduced in 3 to $4 \mathrm{hr}$ with a graphitization yield ranging from 80 to $90 \%$.

The graphite and iron mixture is pressed into a 1-mm hole in an aluminum cathode. To avoid contamination by atmospheric aerosols, this operation is done under a laminar flow hood and the cathodes are kept in glass tubes under argon until measurement.

For some samples like sediments from volcanic areas, marine carbonates, and bioapatite samples (Zazzo et al. 2013), the graphitization process can be slowed down or even stopped by the presence of the halogen or/and sulfur compounds present in these samples. These impurities act as poisons at the surface of the iron catalyst; they prevent the iron carbide $\left(\mathrm{Fe}_{3} \mathrm{C}\right)$ layers formed in the first times of the reduction to break up and, consequently, the development of filamentous carbon under the $\mathrm{Fe}_{3} \mathrm{C}$ particles (Sacco et al. 1984; Santos et al. 2007). The scan-ning electron microscope (SEM) picture (Figure 1), taken from a graphite sample of $1 \mathrm{mg} \mathrm{C}$, shows the filamentous carbon formed during the graphitization process.

In order to clean the $\mathrm{CO}_{2}$ samples that do not reduce to graphite, we can use a chemical reagent called Sulfix (Wako Chemicals Ltd.), mainly constituted of $\mathrm{Co}_{3} \mathrm{O}_{4}$ and $\mathrm{Ag}$ pellets, which traps halogen or sulfur compounds. When the graphitization stops, the gas is frozen by liquid nitrogen in a glass ampoule hooked up to the reactor. As $\mathrm{CO}_{2}$ and $\mathrm{H}_{2}$ are mixed together, it is more difficult to trap $\mathrm{CO}_{2}$ and this step may last up to $30 \mathrm{~min}$. Nevertheless, we observe that only $2 \%$ of the $\mathrm{CO}_{2}$ cannot be frozen and is pumped away with $\mathrm{H}_{2}$. The quartz tube containing iron is replaced by a clean one filled with approximately $500 \mathrm{mg}$ of Sulfix reagent and a plug of silver wool. The line is pumped down to $10^{-5}$ mbar and the reagent degassed at $650^{\circ} \mathrm{C}$ for $45 \mathrm{~min}$

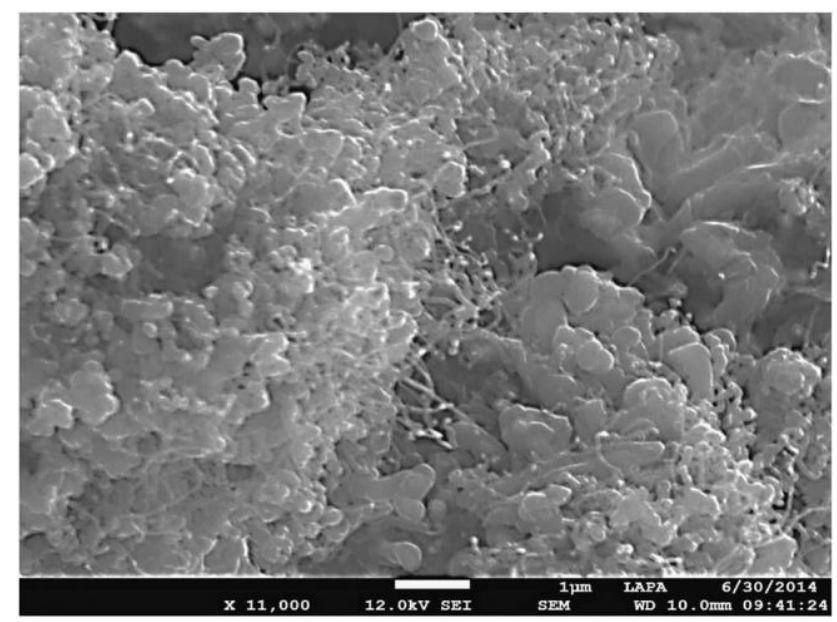

Figure 1 SEM picture of 1-mg C graphite sample. Filamentous carbon is shown under the $\mathrm{Fe} 3 \mathrm{C}$ layers (scale in white bar $=1 \mu \mathrm{m}$ ). 
Table 3 Radiocarbon ages (average values) of ${ }^{14} \mathrm{C}$-free $\mathrm{CO}_{2}$ gas sample and reference samples treated with Sulfix compared with their consensus values. The numbers in parentheses represent the number of aliquots averaged for the result.

\begin{tabular}{|c|c|c|c|c|}
\hline \multirow[b]{2}{*}{ Sample type } & \multicolumn{2}{|c|}{ BP age } & \multicolumn{2}{|c|}{ Consensus BP ages } \\
\hline & Average & $\sigma$ & Average* & $\sigma$ \\
\hline${ }^{14} \mathrm{C}$-free $\mathrm{CO}_{2}$ gas $(8)$ & 47,770 & 2540 & 47,450 & 1590 \\
\hline Firi E (2) & 11,785 & 14 & 11,780 & 7 \\
\hline Firi I (4) & 4504 & 26 & 4485 & 5 \\
\hline Firi H (6) & 2227 & 25 & 2232 & 5 \\
\hline
\end{tabular}

*Average value calculated from the results of aliquots prepared and measured in standard conditions.

under vacuum. The $\mathrm{CO}_{2}$ sample is then transferred from the storage ampoule to the reactor where it is trapped at $-180^{\circ} \mathrm{C}$. The Sulfix reagent is heated again at $650^{\circ} \mathrm{C}$ and the $\mathrm{CO}_{2}$ is expanded in the reactor. These conditions are maintained for $2 \mathrm{hr}$. The cleaned $\mathrm{CO}_{2}$ gas is then trapped in the ampoule for future graphitization.

This cleaning methodology has been used in the laboratory for $10 \mathrm{yr}$. It was demonstrated by dating ${ }^{14} \mathrm{C}$-free $\mathrm{CO}_{2}$ gas using a Sulfix cleaning that the Sulfix reagent had no influence on ${ }^{14} \mathrm{C}$ results. New experiments were performed in 2013 and 2014 on ${ }^{14} \mathrm{C}$-free $\mathrm{CO}_{2}$ gas (supplier: Air Liquide) and reference samples including humic acid FIRI E, cellulose FIRI I, and wood FIRI H. Aliquots of each standard material $\left(8\right.$ of ${ }^{14} \mathrm{C}$-free $\mathrm{CO}_{2}$ gas, 2 of FIRI E, 4 of FIRI I, and 6 of FIRI $\mathrm{H})$ were cleaned with Sulfix reagent in the conditions described above, graphitized, and measured. The results presented in Table 3 show that the average values are perfectly in agreement with the consensus values and confirm that the use of the Sulfix reagent has no influence on ${ }^{14} \mathrm{C}$ dating.

\section{Case of $\mathrm{CO}_{2}$ Provided in Sealed Tubes}

Half of the samples we receive are sent by our partners in $\mathrm{CO}_{2}$ form, sealed in glass tubes. These tubes are stored at room temperature before graphitization. After a few unexpected results for ${ }^{14} \mathrm{C}$ free samples, we suspected that the storage time of the $\mathrm{CO}_{2}$ gas in sealed tubes could be responsible for these results. To test this hypothesis, 18 aliquots of $1 \mathrm{mg} \mathrm{C}$ of the ${ }^{14} \mathrm{C}$-free $\mathrm{CO}_{2}$ gas were collected in sealed glass tubes, kept from 4 up to 113 days in the tubes, and then graphitized. The ${ }^{14} \mathrm{C}$ ages of these aliquots according to the storage time are presented in Figure 2. We do not observe any significant influence of the storage time on the results.

\section{SAMPLE MEASUREMENT AND DATA ANALYSIS}

Two MC-SNICS cesium sputter ion sources with 134 and 40 positions are available in the ARTEMIS AMS facility. The ARTEMIS AMS facility is tuned using routine protocols reported in Moreau et al. (2013). Ten runs of $200 \mathrm{~s}$ are usually done on each sample. Samples are grouped by batches of 20 to 40 , with a limit of 1 day for the measurement of the batch.

Each batch of samples contains one Ox-II every 10 unknown samples and two FIRI calibration samples (Scott 2003). According to the type of the unknown samples, specific blanks are added to the batch (for selection, see blank types in Table 2).

The sample ${ }^{14} \mathrm{C}$ activity is calculated by using ${ }^{12} \mathrm{C},{ }^{13} \mathrm{C}$, and ${ }^{14} \mathrm{C}$ beam currents. The results are normalized to the values of the Ox-II standards present in the batch. The results are given in percent modern carbon (pMC) normalized to a $\delta^{13} \mathrm{C}$ of $-25 \%$. ${ }^{14} \mathrm{C}$ age is calculated using the 


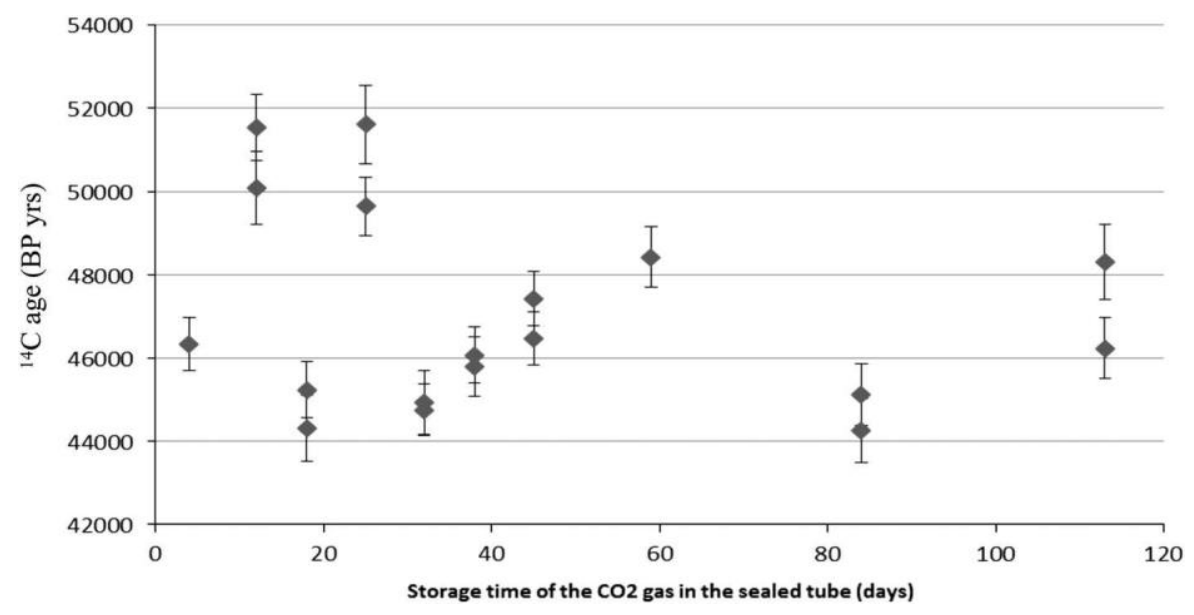

Figure 2 Radiocarbon ages of ${ }^{14} \mathrm{C}$-free $\mathrm{CO}_{2}$ gas samples according to the storage time in sealed glass tubes. These results are not corrected by the machine blank.

Mook and van der Plicht (1999) recommendations, and the $\delta^{13} \mathrm{C}$ fractionation is calculated from the ratio ${ }^{13} \mathrm{C} /{ }^{12} \mathrm{C}$ measured at the ARTEMIS AMS facility. This calculation takes into account all the fractionation processes occurring during the sample preparation and the AMS measurement. An uncertainty is also reported and takes into account the statistical uncertainty and the variability of the subtracted blank level. An individual blank subtraction is done depending on the type of the sample and on the time of storage of the sample between the graphitization process and the AMS measurement (see next paragraph). Results on measured FIRI calibration and blanks are given in Table 2.

In the last $3 \mathrm{yr}$, the blank level has been investigated according to the time of storage and to the mass of the sample. The study of the blank level according to the storage time between the graphitization process and the AMS measurement has been carried out for two types of blank used at LMC14: IAEA C1 and our Border Cave blank wood charcoal. We have chosen routine conditions for the blank preparation. It means that the carbon mass of the studied samples is between 0.3 and $1.7 \mathrm{mg} \mathrm{C}$. Figure 3 shows the behavior of the blank level in pMC according to the storage time. We observe that the blank level increases with time, despite protective storage conditions under argon.

The degradation of the blank level is significant after 60 days of storage. As a consequence, it is reasonable to keep the graphitized samples in the storage less than 2 months. In any case, we aim at the goal to reduce the storage time as short as possible.

Both blanks show a degradation of the blank level according to the time of storage. The data can be fitted by two linear regression curves according to the type of blank.

$$
\text { For IAEA C1 : } \mathrm{pMC}=0: 0010 \text { ' } \mathrm{t}+0: 1386
$$

For charcoal blank : pMC $=0: 0012^{\prime} \mathrm{t}+0: 3043$

where pMC is the percent modern carbon of the sample (in \%) and the storage time (in days) undergone by the sample. 


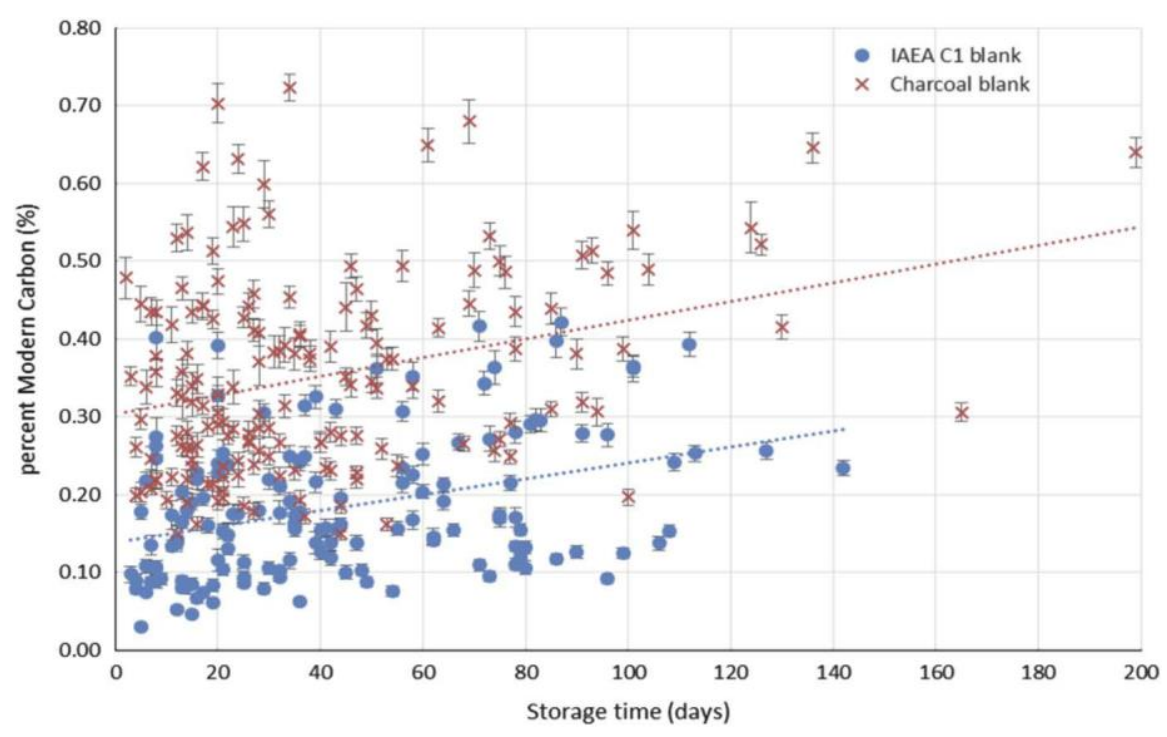

Figure 3 Blank level at LMC14 (with $1 \sigma$ individual error bar) in pMC (in \%) according to the storage time postgraphitization (in days). The dashed line shows the linear regression curve of the data [blue circles (147 targets): IAEA C1; red cross (168 targets): charcoal blank]. Please refer to the online publication for color version.

In both cases, we note that the correlation is weak and that the data variability is large. The scattering of the values apart from the regression lines may come from the preparation process, from the internal variability of the raw material and from the graphitization lines, which are deeply cleaned every 9 months. However, despite the se limitations, we take into account this blank alteration to calculate the date, by routinely using the regression lines for the data ana-lysis. For each ${ }^{14} \mathrm{C}$ result, an individual blank value is calculated as a function of the time of storage of the sample. We have also investigated the blank level according to the mass of the sample; we do not observe any mass dependence in the range $0.3-1.7 \mathrm{mgC}$.

\section{CONCLUSION}

The main objective of this status report was to provide a presentation of the dating process routinely used at the LMC14 as well as to provide information on how to submit a suitable laboratory sample. The laboratory has a long experience for the preparation and the mea-surement of many types of materials: organic matter, carbonates, water, and archaeological iron alloys. Bone preparation is still in progress by comparing several techniques and particularly the ninhydrin method (Nelson 1991; Tisnérat-Laborde et al. 2003) with a modified Longin process (Longin 1971). The first results are very promising (Dumoulin et al., forthcoming).

Chemical protocols are continuously developed to improve our service to the institutions and users. Our line dedicated to organic matter has been modified to allow offline combustion with sealed tubes and a line for DIC extraction from the water has been created. A specific protocol for iron alloys samples has also been developed. A specific procedure is applied for microsamples: standards and blanks with the same range of mass as the sample are produced to control the contamination brought by the preparation protocol. Finally, to solve the 
graphitization problems due to halogens and sulfur compounds, a cleaning methodology of the $\mathrm{CO}_{2}$ sample has been developed.

The quality of the preparation and of the measurements is also continuously controlled and upgraded. The storage duration of the $\mathrm{CO}_{2}$ in Pyrex sealed tubes and the graphite targets have been investigated and taken into account for the ${ }^{14} \mathrm{C}$ results analyses.

All these improvements aim to ensure high-quality results according to the international standard. It is reflected by the very good agreement between the results of our laboratory and the preliminary results of the Sixth International Radiocarbon Intercomparison (SIRI) (Scott et al., forthcoming).

\section{ACKNOWLEDGMENTS}

The authors gratefully acknowledge the contribution of the past and present LMC14 staff and students: D Bavay, N Durand, S Ferkane, B Mollet, A Quiles, M Sieudat, and C Souprayen. The colleagues of the LSCE are thanked for their help and particularly M Fontugne for his useful advice. Two anonymous reviewers are also thanked for their valuable remarks. The LMC14 is funded by five French organizations: CEA, CNRS, IRD, IRSN, and MCC.

\section{REFERENCES}

Bard E, Arnold M, Toggweiler J-R, Maurice P, Duplessy J-C. 1989. Bomb ${ }^{14} \mathrm{C}$ in the Indian Ocean measured by accelerator mass spectro-metry: oceanographic implications. Radiocarbon 31(3):510-22.

Brock F, Higham T, Ditchfield P, Bronk Ramsey C. 2010. Current pretreatment methods for AMS radiocarbon dating at the Oxford Radiocarbon Accelerator Unit (ORAU). Radiocarbon 52(1):102-12.

Cottereau E, Arnold M, Moreau C, Baqué D, Bavay D, Caffy I, Comby C, Dumoulin J-P, Hain S, Perron M, Salomon J, Setti V. 2007. Artemis, the new ${ }^{14} \mathrm{C}$ AMS at LMC14 in Saclay, France. Radiocarbon 49(2):291-9.

Coularis C, Tisnérat-Laborde N, Pastor L, Siclet F, Fontugne M. 2016. Temporal and spatial variations of freshwater reservoir ages in the Loire River watershed. Radiocarbon 58(3):549-63.

Delqué-Količ E, Caffy I, Comby-Zerbino C, Dumoulin J-P, Hain S, Massault M, Moreau C, Quiles A, Setti V, Souprayen C, Tannau J-F, Thellier B, Vincent J. 2013a. Advances in hand-ling small radiocarbon samples at the Laboratoire de Mesure du Carbone 14 in Saclay, France. Radiocarbon 55(2-3):64856.

Delqué-Količ E, Comby-Zerbino C, Ferkane S, Moreau C, Dumoulin J-P, Caffy I, Souprayen C, Quilès A, Bavay D, Hain S, Setti V. 2013b. Preparing and measuring ultra-small radiocarbon samples with the ARTEMIS AMS facility in Saclay, France. Nuclear Instruments and Methods in Physics Research B 294:189-93.

Dumoulin JP, Caffy I, Comby-Zerbino C, DelquéKolič E, Hain S, Massault M, Moreau C, Quiles A, Setti V, Souprayen C, Tannau J-F,
Thellier B, Vincent J. 2013. Development of a line for dissolved inorganic carbon extraction at LMC14 Artemis Laboratory in Saclay, France. Radiocarbon 55(2-3): 1043-9.

Dumoulin J-P, Messager C, Valladas H, Beck L, Caffy I, Delqué-Količ E, Moreau M, Lebon M. First investigations to compare two bone pre-paration methods for radiocarbon dating: Longin and Ninhydrin. Radiocarbon, forthcoming.

Fontugne M. 2013. New radiocarbon ages of Luzia woman, Lapa Vermelha IV site, Lagoa Santa, Minas Gerais, Brazil. Brazil. Radiocarbon 55(23):1187-90.

Fontugne M, Shao Q, Frank N, Thil F, Guidon N, Boëda E. 2013. Cross-dating (Th/U_ $\left.{ }^{14} \mathrm{C}\right)$ of calcite covering prehistoric paintings at Serra da Capivara National Park, Piaui, Brazil. Radiocarbon 55(23):1191-8.

Genty D, Konik S, Valladas H, Blamart D, Hellstrom J, Touma M, Moreau C, Dumoulin J-P, Nouet J, Dauphin Y, Weil R. 2011. Dating the Lascaux Cave gourformation. Radiocarbon 53(3):479-500.

Gillespie R. 1984. Radiocarbon User's Handbook, Monograph 3. Oxford: Oxford University Committee for Archeology.

Goh KM, Molloy BPJ. 1972. Reliability of radiocarbon dates from buried charcoals. Proceedings of the 8th International Conference on Radiocarbon Dating. Volume 2. Wellington: The Royal Society of New Zealand.

Hatté C, Morvan J, Noury C, Paterne M. 2001. Is classical acid-alkali-acid treatment responsible for contamination? An alternative proposition. Radiocarbon 43(2A): 177-82.

Hatté C, Poupeau J-J, Tannau J-F, Paterne M. 2003. Development of an automated system for 
preparation of organic samples. Radiocarbon 45(3):421-30.

Hatté C, Gauthier C, Rousseau D-D, Antoine P, Fuchs M, Lagroix F, Markovic S-B, Moine O, Sima A. 2013. Excursions to $\mathrm{C} 4$ vegetation recorded in the Upper Pleistocene loess of Surduk (Northern Serbia): an organic isotope geochemistry study. Climate of the Past 9:1001-14.

Hüls CM, Grootes PM, Nadeau M-J, Bruhn F, Hasselberg P, Erlenkeuser H.. 2004. AMS radiocarbon dating of iron artefacts. Nuclear Instruments and Methods in Physical Research B 223-224:709-15.

Leboucher V, Jean-Baptiste P, Fourré E, Arnold M, Fieux M. 2004. Oceanic radiocarbon and tritium on a transect between Australia and Bali (eastern Indian Ocean). Radiocarbon 46(2):567-81.

Leroy S, L'Héritier M, Delqué-Kolic E, Dumoulin J-P, Moreau C, Dillmann P.. 2015. Consolidation or initial design? Radiocarbon dating of ancient iron alloys sheds light on the reinforcements of French Gothic cathedrals. Journal of Archaeological Science 53:190-201.

Longin R. 1971. New method of collagen extraction for radiocarbon dating. Nature 230(5291):241-2.

Mook WG, van der Plicht J. 1999. Reporting ${ }^{14} \mathrm{C}$ activities and concentrations. Radiocarbon 41(3):227-39.

Moreau C, Caffy I, Comby C, Delqué-Količ E, Dumoulin J-P, Hain S, Quiles A, Setti V, Souprayen C, Thellier B. 2013. Research and development of the Artemis ${ }^{14} \mathrm{C}$ AMS Facility: status report. Radiocarbon 55(2-3):331-7.

Nelson DE. 1991. A new method for carbon isotopic analysis of protein. Science 251(4993):552-4.

Quiles A, Aubourg E, Berthier B, Delque-Količ E, Pierrat-Bonnefois G, Dee MW, Andreu-Lanoë G, Bronk Ramsey C, Moreau C. 2013. Bayesian modelling of an absolute chronology for Egypt's 18 th Dynasty by astrophysical and radiocarbon methods. Journal of Archaeological Science 40(1):423-32.

Richardin P, Coudert M, Gandolfo N, Vincent J. 2013. Radiocarbon dating of mummified human remains: application to a series of Coptic mum-mies for the Louvre Museum. Radiocarbon 55(2-3):345-52.
Sacco A, Thacker P, Chang TN, Chiang TS. 2004. The initiation and growth of filamentous carbon from alpha-iron in $\mathrm{H}_{2}, \mathrm{CH}_{4}, \mathrm{H}_{2} \mathrm{O}, \mathrm{CO}_{2}$ and $\mathrm{CO}$ gas mixtures. Journal of Catalys is 85:224-36.

Santos GM, Southon JR, Griffin S, Beaupre SR, Druffel ERM. 2007. Ultra small-mass AMS ${ }^{14} \mathrm{C}$ sample preparation and analyses at KCCAMS/ UCI Facility. Nuclear Instruments and Methods in Physics Research B 259(1):293-302.

Scott EM. 2003. The fourth international radiocarbon intercomparis on (FIRI). Section 10: summary and conclusions. Radiocarbon 45(2):285-90.

Scott EM, Cook G, Naysmith P. 2017. Should archaeologists care about ${ }^{14} \mathrm{C}$ intercomparisons? Why? A summary report on SIRI. Radiocarbon, forthcoming.

Tisnérat-Laborde N, Poupeau J-J, Tannau J-F, Paterne M. 2001. Development of a semi-automated system for routine preparation of carbonate samples. Radiocarbon 43(2A):299-304.

Tisnérat-Laborde N, Valladas H, Kaltnecker E, Arnold M. 2003. AMS radiocarbon dating of bones at LSCE. Radiocarbon 45(3):409-19.

Tisnérat-Laborde N, Montagna P, Frank N, Siani G, Silenzi S, Paterne M. 2013. A high-resolution coral-based delta ${ }^{14} \mathrm{C}$ record of surface water processes in the western Mediterranean Sea. Radiocarbon 55(2-3): 1617-30.

Valladas H, Genty D, Kaltnecker E, Quiles A, TisnératLaborde N, Arnold M, Delqué-Količ E, Moreau C, Baffier D, Cleyet Merle J-J, Clottes J, Girard M, Monney J, Montes R, Sainz C, Sanchidrian JL, Simonnet R. 2013. Dating French and Spanish prehistoric decorated caves in their archaeological contexts. Radiocarbon 55(2-3):1422-31.

Vogel JS, Southon JR, Nelson DE, Brown TA. 1984. Performance of catalytically condensed carbon for use in accelerator mass spectrometry. Nuclear Instruments and Methods in Physics Research B 5(2):289-93.

Zazzo A, Lebon M, Chiotti L, Comby C, Delqué-Količ E, Nespoulet R, Reiche I. 2013. Can we use calcined bones for radiocarbon Dating the Paleolithic? Radiocarbon 55(2-3):1409-21. 